\title{
Distribution and morphology of growth anomalies in Acropora from the Indo-Pacific
}

\author{
Thierry M. Work ${ }^{1, *}$, Greta S. Aeby ${ }^{2}$, Steve L. Coles ${ }^{3}$ \\ ${ }^{1}$ US Geological Survey, National Wildlife Health Center, Honolulu Field Station, 300 Ala Moana Blvd., Room 5-231, \\ Honolulu, Hawaii 96850, USA \\ ${ }^{2}$ Hawaii Institute of Marine Biology, University of Hawaii, PO Box 1346, Kaneohe, Hawaii 96744, USA \\ ${ }^{3}$ Bishop Museum, 1525 Bernice Street, Honolulu, Hawaii 96817, USA
}

\begin{abstract}
We assessed the distribution and prevalence of growth anomalies (GAs) in Acropora from French Frigate Shoals (Hawaii, USA), Johnston Atoll and Tutuila (American Samoa), developed a nomenclature for gross morphology, characterized GAs at the cellular level and obtained preliminary indices of their spatial patterns and progression within coral colonies. Acropora GAs were found in all 3 regions, but the distribution, variety and prevalence of Acropora GAs was highest in American Samoa. GAs were grouped into 7 gross morphologies (exophytic, bosselated, crateriform, nodular, vermiform, fimbriate or annular). On histology, GAs consisted of hyperplastic basal body wall (calicodermis, mesoglea and gastrodermis apposed to skeleton) with 3 distinct patterns of necrosis. There was no evidence of anaplasia or mitotic figures (common but not necessarily required morphologic indicators of neoplasia). Compared to normal tissues, GAs had significantly fewer polyps, zooxanthellae within the gastrodermis of the coenenchyme, mesenterial filaments and gonads but significantly more necrosis. On 2 colonies with GAs monitored at 2 points over 11 mo, numbers of GAs per colony increased from 0.9 to 3 times the original number seen, and significant clustering of GAs occurred within colonies. The evidence of GAs being true neoplasias (tumors) is mixed, so a cautionary approach is urged in use of morphologic terminology.
\end{abstract}

KEY WORDS: Acropora · Growth anomaly · Epizootiology · Johnston Atoll · French Frigate Shoals · American Samoa

Resale or republication not permitted without written consent of the publisher

\section{INTRODUCTION}

Diseases are an emerging issue in coral reef ecosystems, but little fundamental knowledge exists on their morphology, their causes or options for their management. This has been partly due to lack of standardized case definitions, descriptions and nomenclature (Work \& Aeby 2006). One easily recognizable disease of scleractinian corals is growth anomalies (GAs) that present as protuberant masses on the coral skeleton. GAs on corals were first seen in Madrepora kauaiensis collected in 1902 from Hawaii, USA (Squires 1965). Since then GAs have been reported in a variety of coral genera from both the Caribbean and the Indo-Pacific (Peters 1997, Sutherland et al. 2004). In Acropora GAs have been seen in the Florida Keys (Peters et al. 1986), Caribbean (Bak 1983), Gulf of Oman (Coles \& Seapy 1998), American Samoa (Work \& Rameyer 2005), Guam, Enewetak (Cheney 1975) and Australia (Willis et al. 2004).

Acropora GAs are characterized by reduced colony growth (Cheney 1975, Bak 1983), decreased density of coral skeleton (Cheney 1975, Bak 1983) and reduced numbers of zooxanthellae (Cheney 1975, Peters et al. 1986). Peters et al. (1986), in the first systematic descriptions of GAs cellular morphology, found them to consist mainly of basal body wall (the tissue apposed to skeleton and comprising calicodermis, mesoglea and gastrodermis) with reduced or absent polyp formation, increased cellular density and decreased numbers of 
zooxanthellae. Based on the relatively rapid growth of GAs compared to normal tissues (Cheney 1975, Bak 1983, Peters et al. 1986) and their irreversible growth leading to death, Peters et al. (1986) concluded that GAs in A. palmata were true neoplasms. Acropora GAs do not appear to be transmissible (Cheney 1975, Peters et al. 1986).

To begin elucidating the etiology and epizootiology of Acropora GAs, it would be useful to have standardized morphologic criteria that could be applied to the field. Characterizing GAs at the spatial, gross and microscopic levels may also provide valuable clues to their biology. Accordingly our objectives were to (1) determine distribution and prevalence of GAs in Acropora from across the Indo-Pacific Ocean (French Frigate Shoals [FFS]; Johnston Atoll and Tutuila [American Samoa]); (2) develop a nomenclature for gross morphology of GAs; (3) characterize GAs at the cellular level; and (4) determine whether GAs were clustered within corals.

\section{MATERIALS AND METHODS}

Field surveys. FFS is part of the Northwestern Hawaiian Islands and consists of a barrier reef partially enclosing a lagoon with 2 permanent emergent low islands (Tern and East Island) and several ephemeral sand bars. Tern and East Island experienced heavy activity during World War II (WW II), and Tern Island was a US Coast Guard LORAN (Long Range Aids to Navigation) station until the early 1980s. FFS is now a national wildlife refuge (NWR) with a small ( $<5$ person) staff on Tern Island (Amerson 1971). Dominant corals at FFS include Porites, Acropora and Pocillopora (Kenyon et al. 2006). Johnston Atoll NWR is located ca. $1154 \mathrm{~km}$ southwest of Honolulu, Hawaii, and is part of the Marcus-Necker Rise. Johnston Atoll has 4 islands, 3 of which are manmade and all of which saw significant military activity during WW II and the Vietnam War (Amerson \& Shelton 1976). Dominant corals at Johnston Atoll include
Acropora and Montipora (Maragos \& Jokiel 1986). Tutuila is a volcanic island within American Samoa surrounded by shallow-water fringing coral reefs. Tutuila supports a high human population (ca. 1300 people $\mathrm{km}^{-2}$ ), and its coral reefs harbor a large diversity of corals reflective of a tropical Indo-Pacific reef (Mundy 1996, Green et al. 1999).

Surveys were conducted at multiple sites at FFS, Johnston Atoll and Tutuila in 2004 (Table 1). At each site 2 consecutive $25 \mathrm{~m}$ lines, separated by ca. $5 \mathrm{~m}$, were laid out along depth contours (3 to $15 \mathrm{~m}$ ). Coral community structure was documented along the transect lines by recording coral colonies by size class $(0$ to $5,>5$ to $10,>10$ to $20,>20$ to $40,>40$ to $80,>80$ to 160 and $>160 \mathrm{~cm}$ ). Width of the belt transect for colony counts was either 1 or $2 \mathrm{~m}$ depending on colony density and time available for surveys. All Acropora with GAs were described, enumerated and photographed along a $25 \times 6 \mathrm{~m}$ belt that overlapped the transect used for colony counts. We estimated the total number of Acropora colonies surveyed for disease based upon the average number of colonies $\mathrm{m}^{-2}$ found within the $25 \times$ 1 or $2 \mathrm{~m}$ belt transect where colony counts were done as: $\left(\mathrm{avg}\right.$. no. of corals $\left.\mathrm{m}^{-2}\right) \times\left(\right.$ total area $\left[\mathrm{m}^{2}\right]$ surveyed for disease). Prevalence of Acropora GAs for each site was calculated as: [(no. of Acropora with GAs)/(total no. of Acropora)] $\times 100$. Frequency of Acopora GAs disease occurrence (FDO) was calculated as: [(no. of sites with Acropora GAs)/(total no. of sites surveyed containing Acropora)] $\times 100$. Percent coral cover was estimated using the line-intercept method (documenting substrate every $10 \mathrm{~cm}$ along the transect line) at FFS and Tutuila and visually at Johnston Atoll.

Morphology. Description and histology of GAs were based on photographs and collection of samples from studies in each of the 3 regions between 2002 and 2006. Corals with GAs were photographed and collected as described in Work \& Rameyer (2005) and classified based on gross morphology (Work \& Aeby 2006). Tissue samples were preserved in ZincFormaldehyde solution (Z-Fix, Anatech) diluted 1:5 in seawater, decalcified in CalEx-II (Fisher Diagnos-

Table 1. Site coordinates, survey dates, no. of sites surveyed for each region, mean depths of transects, percent coral cover, mean density and percent of Acropora, frequency of disease occurrence (FOD), and prevalence of growth anomalies (GAs) in Acropora partitioned by 3 regions in the Indo-Pacific

\begin{tabular}{|c|c|c|c|c|c|c|c|c|c|}
\hline \multirow{2}{*}{ Region } & \multirow{2}{*}{ Location } & \multirow{2}{*}{$\begin{array}{c}\text { Dates } \\
\text { surveyed }\end{array}$} & \multirow{2}{*}{$\begin{array}{l}\text { No. of } \\
\text { sites }\end{array}$} & \multirow{2}{*}{$\begin{array}{l}\text { Mean } \\
\text { depth }(\mathrm{m}) \\
(\mathrm{SE})\end{array}$} & & & \multirow{2}{*}{$\begin{array}{l}\text { Acropora } \\
\text { Acropora } \\
(\%)(\mathrm{SE})\end{array}$} & \multirow[b]{2}{*}{$\begin{array}{l}\text { FOD } \\
(\%)\end{array}$} & \multirow[b]{2}{*}{$\begin{array}{c}\text { Disease } \\
\text { prevalence }\end{array}$} \\
\hline & & & & & $\begin{array}{c}\text { Coral } \\
\text { cover }(\%)\end{array}$ & $\begin{array}{l}\text { Colonies } \mathrm{m}^{-2} \\
\text { (SE) }\end{array}$ & & & \\
\hline $\begin{array}{l}\text { French Frigate } \\
\text { Shoals }\end{array}$ & $23^{\circ} \mathrm{N}, 166^{\circ} \mathrm{W}$ & Sep 2004 & 11 & $7(1)$ & 1 to 53 & $0.41(0.19)$ & $19.4(8.9)$ & 33 & 0 \\
\hline Johnston Atoll & $16^{\circ} \mathrm{N}, 169^{\circ} \mathrm{W}$ & Jan 2004 & 12 & $8(0.9)$ & 10 to 80 & $0.42(0.08)$ & $9.6(2.6)$ & 0 & 0 \\
\hline Tutuila & $14^{\circ} \mathrm{S}, 170^{\circ} \mathrm{W}$ & Jun 2004 & 7 & $7(0.5)$ & 23 to 48 & $0.58(0.11)$ & $10.4(2.2)$ & 58 & 0 to 3 \\
\hline
\end{tabular}


tics) and processed for histology (Work \& Rameyer 2005). We quantified differences in tissues between GAs and paired normal tissues using photogrammetry (SigmaScan, SPSS). To get an index of the difference in polyp numbers between GAs and normal tissues, numbers of polyps in normal versus GA tissues were counted using a square grid superimposed on a close-up photograph of a lesion encompassing both normal and abnormal tissue (Fig. 1A). Each square on the photo was adjusted to approximate the surface area of a polyp. Polyps were counted in normal and GA areas, and total numbers of squares counted for each area were recorded. We then standardized polyp counts as numbers of squares with polyps divided by total squares counted for GAs versus normal areas.

To quantify changes in tissues at the cellular level, microscope slides containing tissue sections stained with hematoxylin and eosin were scanned using a slide scanner (Nikon CoolScan IV ED, Nikon). We calculated percent mesenterial filaments based on total tissue area for a standardized area of tissue $\left(100 \mu^{2}\right)$ (SigmaScan). Zooxanthellae within the gastrodermis and spirocysts within epidermis were counted along a contour length (CL) of coenenchyme. Similarly, to quantify cellular changes in basal body wall, the number of calicodermal and gastrodermal nuclei were counted for a given CL of basal body wall. We normalized counts of zooxanthellae, nuclei and spirocysts by dividing numbers of each of these structures by CL (no. of structures/unit length tissues) for GAs versus normal tissues.

Because quantitative data of polyp counts and cellular structures failed to meet assumptions of equal variance and normality, we used the Mann-Whitney $U$-test to compare GAs and normal tissues for normalized counts of polyps, spirocysts and zooxanthellae in coenenchyme, nuclei in basal body wall and percent mesenterial filaments based on total tissue area. To account for repeated tests for each specimen (lack of independence), a Bonferonni adjustment of alpha ( $\alpha=$ 0.01 ) was made for $n=5$, the number of parameters being compared (Rice 1989). We used the chi square test to see if a significant association existed among GAs and normal tissue and the presence of gonads or necrosis. Analysis of variance was used to compare Acropora $\mathrm{m}^{-2}$ and mean survey depths among FFS, Johnston Atoll, and Tutuila.

To evaluate clustering within colonies, 2 plating Acropora colonies (one from Johnston Atoll and another from Tutuila) were photographed from the top and the distribution of GAs were analyzed. We used nearest-neighbor analysis (Clark \& Evans 1954) to see if spatial distribution of GAs deviated significantly from random (clustering) within colonies.

\section{RESULTS}

Acropora cover ranged from a low of $9.6 \%$ at Johnston Atoll to ca. $20 \%$ at FFS, but average Acropora colony density and survey depths did not differ significantly across regions (Table 1). Tutuila had the highest FDO and highest prevalence of Acropora GAs. Although Acropora GAs were seen at Johnston Atoll and FFS, they were not found within the belt transects we surveyed, thus explaining the zero prevalence for both regions (Table 1).

GAs were found on more than 10 species of Acropora representing the major colony morphs of this genus (plating, encrusting, branching and corymbose) (Table 2). The size of colonies affected by GAs ranged from $<50 \mathrm{~cm}$ to $>2 \mathrm{~m}$. Numbers of GAs per colony ranged from 1 to $>100$, and size of individual GAs ranged from $<1$ to $>35 \mathrm{~cm}$ in diameter. For branching colonies GAs were found on all parts of the colonies, whereas for plating colonies GAs were distributed chiefly on the upper surface. Two colonies with GAs photographed in February 2005 and January 2006 experienced varying levels of tissue loss, and the numbers of GAs increased from 13 to 40 in one instance and 11 to 20 GAs in another during 11 mo. Tissue loss was most often seen in larger GAs (Fig. 2B,F). Within colonies distribution of GAs was significantly clustered ( $\mathrm{p}<0.05$ ) for 2 plating Acropora from Johnston Atoll and Tutuila. Regression of GAs over time was not seen.

Seven morphologic types of Acropora GAs were observed (exophytic, bosselated, crateriform, nodular, vermiform, fimbriate and annular) (Fig. 1). Based upon a representative sub-sample of 54 GAs photographed in the field, the most common type of GA was exophytic $(44.4 \%)$ with this morphology found on 8 Acropora species including encrusting $(100 \%)$, branching $(62 \%)$ and plating (52\%) colonies; bosselated GAs were most commonly found on corymbose colonies. All 7 morphologies of GAs were found in Tutuila, compared to 2 types of GAs found at FFS (exophytic and vermiform) and only 1 type of GAs (exophytic) found at Johnston Atoll (Table 2).

Polyps were quantified for 41 paired GAs and normal tissues, and GAs had significantly fewer polyps per unit area than normal tissues (MannWhitney $U, T=2486, \mathrm{p}<0.0001$ ). Microscopic cellular changes were quantified for paired tissues from 16 normal and 16 GAs including 2 nodular, 3 crateriforms, 5 bosselated and 6 exophytic GAs. Compared to normal tissues, tissues from GAs had significantly fewer zooxanthellae in the upper body wall of the coenenchyme (Mann-Whitney $U, T=359$, p < 0.001) and a lower percent of mesenterial filaments based on total tissue area (Mann-Whitney $U, T=169, \mathrm{p}<$ 0.001). We saw no significant difference in the 

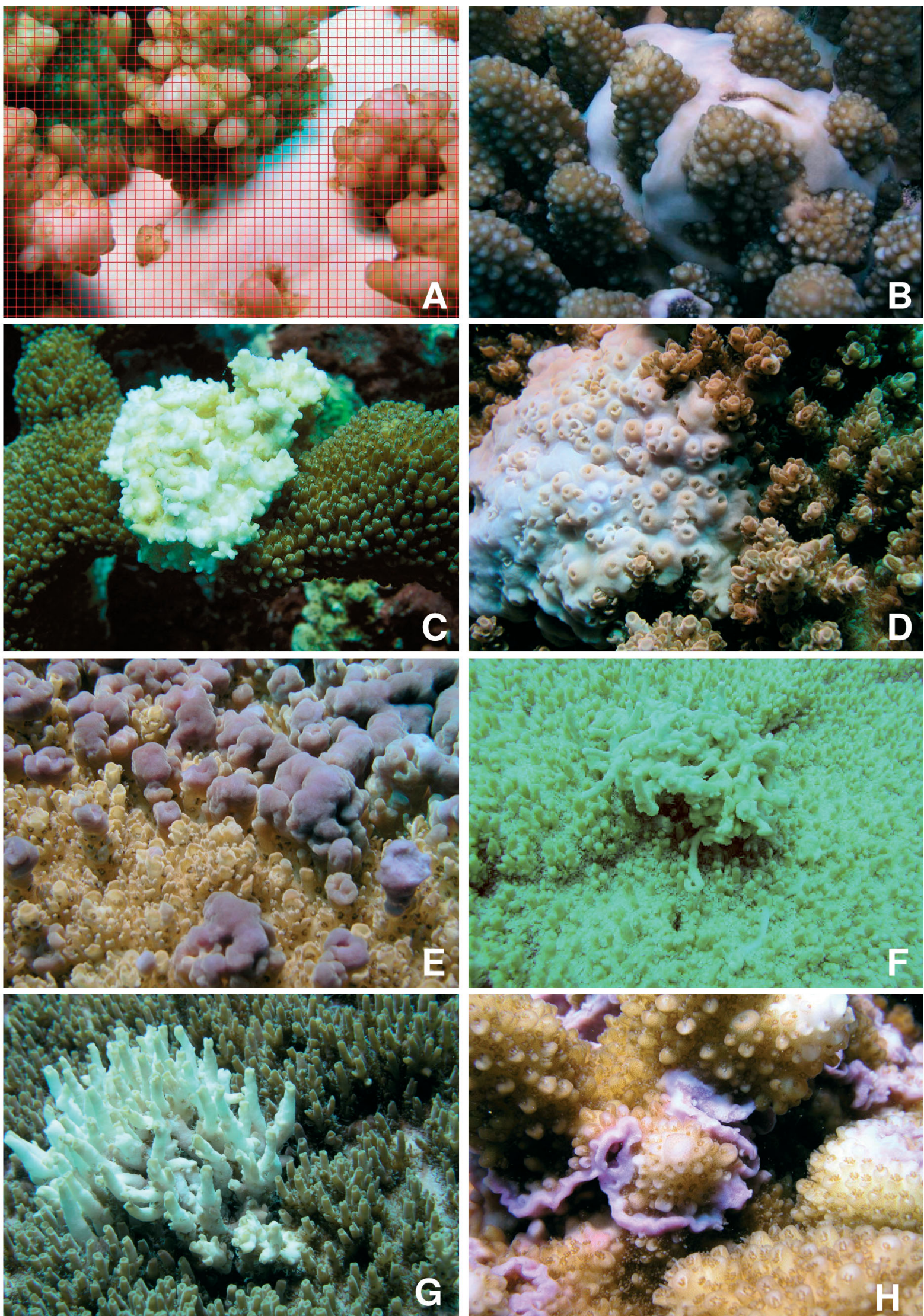
Fig. 1. Acropora spp. (A) Example of grid overlay on photograph used to quantify polyps in normal versus growth anomaly (GA) areas. (B to H) GAs in Acropora. (B) Bosselated GAs in Acropora sp.: skeletal growths with smooth to undulating surface located principally at base of branches and covered by translucent tissue usually lacking polyps. (C) Exophytic GAs in A. abrotenoides: sessile skeletal growths with rugose to papillary surface sometimes containing partially formed disorganized to chaotic exert calices covered by translucent tissue (appears white as skeleton is present under the tissue) with sparse polyp formation. (D) Crateriform GAs in A. hyacinthus: sessile skeletal growths with smooth undulating surface having low to recessed variably sized calices, reduced to vestigial polyps, and covered by blue-white smooth tissue. (E) Nodular GAs in A. hyacinthus: sessile to slightly pedunculated, isolated to coalescing, round to elliptical, skeletal growths covered with grey tissue lacking polyps. (F) Vermiform GAs in A. cytherea: skeletal growths similar to exophytic GAs but with most calices elongated, intertwining to serpiginous, and covered by white or pigmented tissue with sparse to no polyp formation. (G) Fimbriated GAs in Acropora sp.: skeletal growths consisting of slightly diverging or parallel elongated calices that are markedly thickened with irregular walls and covered by white tissue with rare polyps at the base. (H) Annular GAs in A. cf. monticulosa: narrow serpentine shelf-like skeletal GAs meandering at base of branches, partially or completely circumscribing the branch base, and covered by pink tissue lacking polyps

numbers of spirocysts or numbers of calicodermal or gastrodermal nuclei between GAs and normal tissues (Table 3).

Five of the 7 morphologic types of GAs (exophytic, bosselated, crateriform, nodular and vermiform) showed a consistent pattern of microscopic morphology, which included hyperplasia of cells of the polyp's basal body walls (consisting of the calicodermis, mesoglea and gastrodermis covering the exoskeleton of scleractinian coral) with reduced to absent polyp structures and lack of or reduced numbers of zooxanthellae (Fig. 3A,B). Significantly more necrosis $\left(\chi^{2}=\right.$ 10.96, p < 0.001) was present in GAs (56\%) versus normal tissues $(0 \%)$, whereas significantly fewer gonads $\left(\chi^{2}=9.64, p=0.002\right)$ were present in GAs $(0 \%)$ versus normal tissues $(50 \%)$. Within GAs 3 pat- terns of necrosis were evident. Mild to severe selective necrosis of partial or entire mesenterial filaments was present in 3 exophytic and 1 nodular GAs and was characterized by cellular rounding, pyknosis, cytoplasmic hypereosophilia, dissociation and karyorrhexis (Fig. 3C). Mild to severe diffuse necrosis of basal body walls including mesenterial filaments was seen in 1 annular, 2 bosselated and 6 exophytic GAs (Fig. 3D), of which 2 cases of necrosis were accompanied by mixed fungi and algae infiltrating skeleton and tissues. Mild to severe diffuse necrosis of basal body wall with deposition of layers of hyaline material was seen in 1 nodular (Fig. 3E), 1 fimbriate, 4 bosselated and 8 exophytic GAs, of which 7 cases of necrosis were accompanied by fungi or filamentous algae infiltrating skeleton and tissues. In 1 crateriform GA

Table 2. Acropora spp. Number of colonies partitioned by morphology of growth anomalies (GAs), colony morphology and species for French Frigate Shoals (FFS), Johnston Atoll and Tutuila (American Samoa)

\begin{tabular}{|c|c|c|c|c|c|c|c|c|}
\hline \multirow{2}{*}{$\begin{array}{l}\text { Colony morph } \\
\text { Species }\end{array}$} & \multirow[b]{2}{*}{ Exophytic } & \multirow[b]{2}{*}{ Bosselated } & \multirow[b]{2}{*}{ Crater } & \multicolumn{2}{|c|}{ Morphologic type of GAs } & \multirow[b]{2}{*}{ Fimbriated } & \multirow[b]{2}{*}{ Annular } & \multirow{2}{*}{ Total } \\
\hline & & & & Nodular & Vermiform & & & \\
\hline \multicolumn{9}{|l|}{ Branching } \\
\hline A. abrotenoides & 5 & 0 & 0 & 1 & 2 & 0 & 0 & 8 \\
\hline \multicolumn{9}{|l|}{ Encrusting } \\
\hline A. crateriformis & 2 & 0 & 0 & 0 & 0 & 0 & 0 & 2 \\
\hline \multicolumn{9}{|l|}{ Plating } \\
\hline A. cytherea & 9 & 2 & 0 & 0 & 1 & 1 & 0 & 13 \\
\hline A. hyacinthus & 4 & 2 & 6 & 1 & 0 & 0 & 0 & 13 \\
\hline A. clathrata & 1 & 0 & 0 & 0 & 0 & 0 & 0 & 1 \\
\hline Acropora sp. & 1 & 1 & 0 & 0 & 0 & 0 & 0 & 2 \\
\hline Subtotal plating & 15 & 5 & 6 & 1 & 1 & 1 & 0 & 29 \\
\hline \multicolumn{9}{|l|}{ Corymbose } \\
\hline A. cf. humilis & 0 & 1 & 0 & 0 & 0 & 0 & 1 & 2 \\
\hline A. digitifera & 0 & 1 & 0 & 0 & 0 & 0 & 0 & 1 \\
\hline A. listeri & 1 & 0 & 0 & 0 & 0 & 0 & 0 & 1 \\
\hline A. monticulosa & 0 & 0 & 1 & 0 & 0 & 0 & 0 & 1 \\
\hline A. samoensis & 0 & 1 & 0 & 0 & 0 & 0 & 0 & 1 \\
\hline Acropora sp. & 1 & 5 & 1 & 1 & 0 & 1 & 0 & 9 \\
\hline Subtotal corymbose & 2 & 8 & 2 & 1 & 0 & 1 & 1 & 15 \\
\hline Grand total & 24 & 13 & 8 & 3 & 3 & 2 & 1 & 54 \\
\hline
\end{tabular}



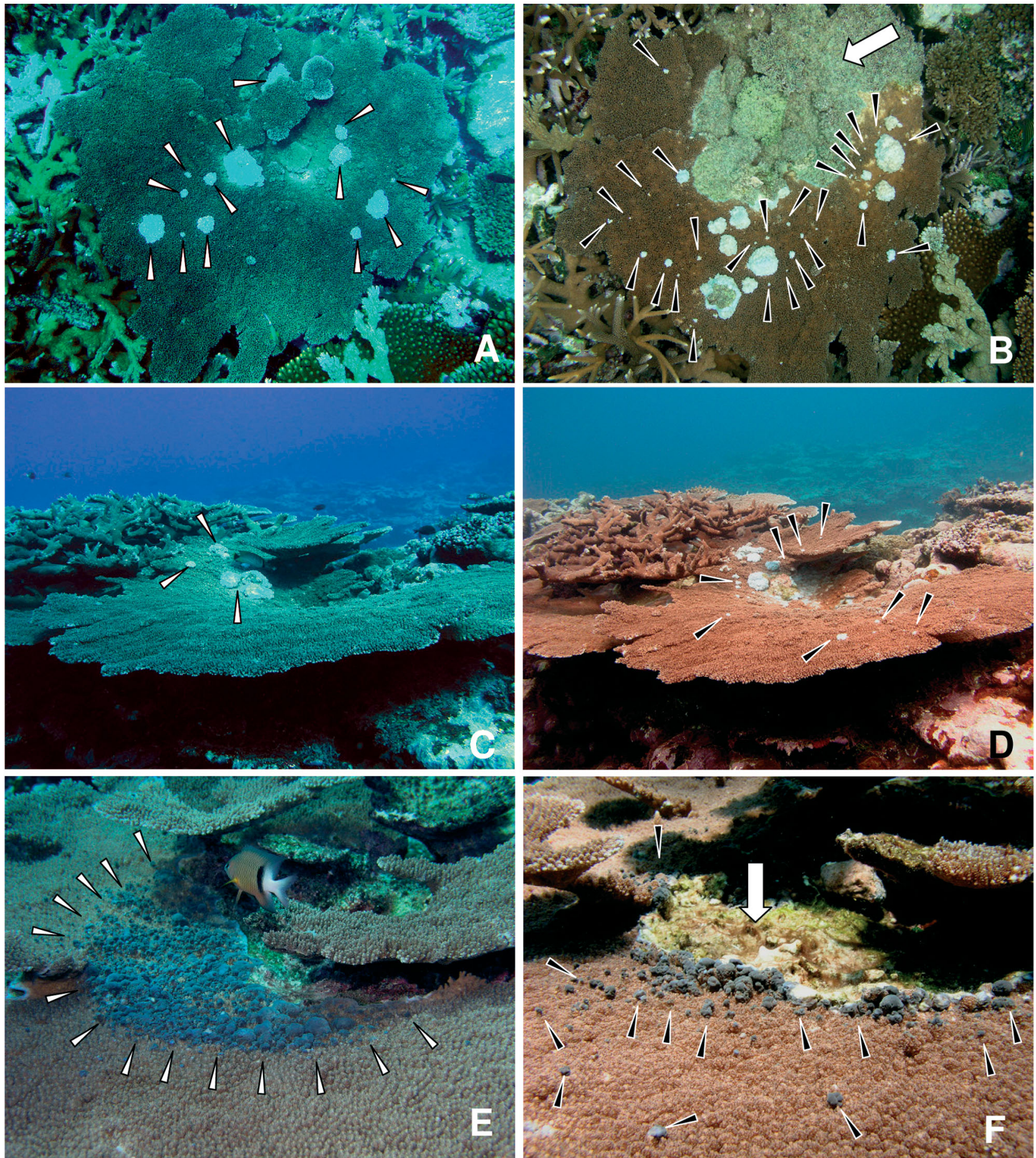

Fig. 2. Acropora spp. Paired photos from Tutuila (American Samoa) with growth anomalies (GAs) in (A,C,E) February 2005 and $(\mathrm{B}, \mathrm{D}, \mathrm{F})$ January 2006. $(\mathrm{A}, \mathrm{C}, \mathrm{E})$ White arrows indicate original GAs and $(\mathrm{B}, \mathrm{D}, \mathrm{F})$ black arrows indicate new growths 11 mo later (not all growths indicated). (B \& F) Large white block arrows indicate tissue loss. (A \& B) Exophytic GAs in Acropora sp. (C \& D) Exophytic GAs in A. hyacinthus. (E \& F) Nodular GAs in A. hyacinthus

large masses of endolithic sponges were present within the skeleton (Fig. 3F). We saw no recognizable difference in microscopic morphology between fimbriate GAs and normal tissue, and diffuse necrosis associated with hyaline material was the only significant finding in the single annular GAs examined. Anaplasia, prominent nucleoli, cellular invasiveness or mitotic figures were not seen in any of the GAs. 
Table 3. Acropora spp. Mean (SD); median (italics) cellular morphometrics for paired tissues from areas with $(\mathrm{n}=16)$ and without $(n=16)$ growth anomalies (GAs). cg: coenosarc gastrodermis; bbw: basal body wall; percent mesenterial filaments based on total tissue area. * Significant differences between tissues without and with GAs (Mann-Whitney $U, \mathrm{p}<0.01$ )

\begin{tabular}{|lccccc|}
\hline Tissue & $\begin{array}{c}\text { Polyps per } \\
\text { unit area }\end{array}$ & $\begin{array}{c}\text { Zooxanthellae per } \\
\text { unit length cg }\end{array}$ & $\begin{array}{c}\text { Spirocysts per } \\
\text { unit length cg }\end{array}$ & $\begin{array}{c}\text { Coral cell nuclei per } \\
\text { unit length bbw }\end{array}$ & $\begin{array}{c}\text { Percent mesenterial } \\
\text { filaments }\end{array}$ \\
\hline $\begin{array}{l}\text { Normal } \\
\text { GAs }\end{array}$ & $0.195(0.11)^{*} ; 0.182$ & $1.191(1.198)^{*} ; 0.868$ & $0.493(0.737) ; 0.184$ & $1.769(0.685) ; 1.9$ & $0.234(0.141)^{*} ; 0.2$ \\
& $0.023(0.0313)^{*} ; 0.0122$ & $0.329(0.358)^{*} ; 0.223$ & $0.329(0.537) ; 0.0563$ & $1.944(1.023) ; 1.649$ & $0.0773(0.0895)^{*} ; 0.0415$ \\
\hline
\end{tabular}
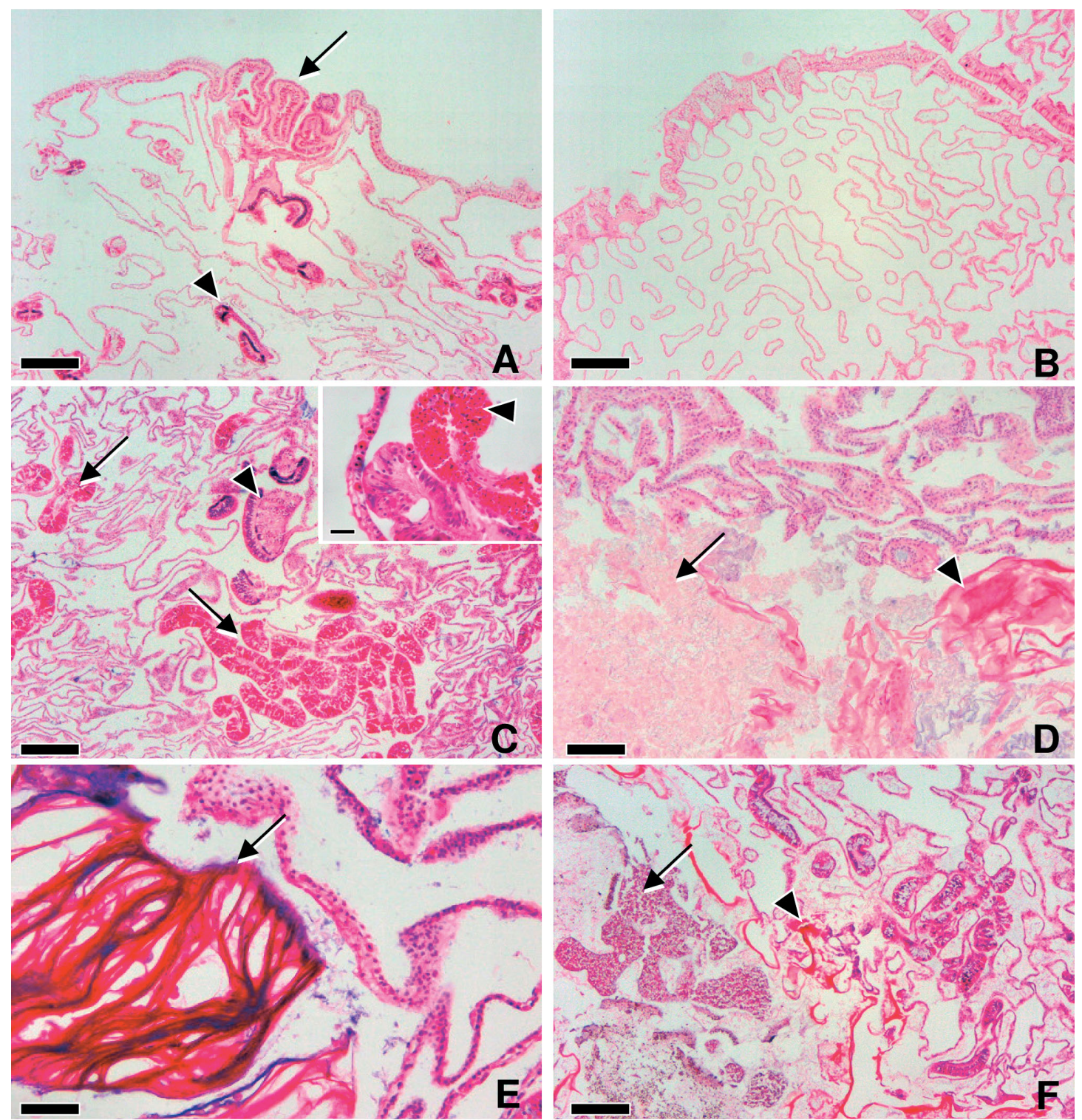

Fig. 3. Acropora spp. Tissue sections of corals stained with haematoxylin and eosin. (A) Corymbose normal tissue; note polyp (black arrow) and mesenterial filaments (arrowhead); scale bar $=200 \mu \mathrm{m}$. (B) Bosselated growth anomalies (GAs) from same coral in $(\mathrm{A})$; note lack of mesenterial filaments and polyps and generally uniform presence of basal body wall forming gastrovascular canal network; scale bar $=200 \mu \mathrm{m}$. (C) Exophytic GAs from A. abrotenoides; note selective necrosis of mesenterial filaments exemplified by cytoplasmic rounding, hypereosinophilia and pyknosis (arrows) compared to normal filaments (arrowhead); scale

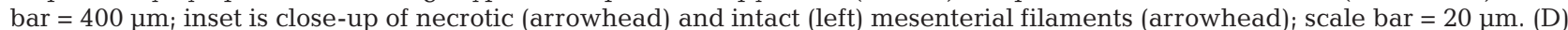
Same as (C); note coagulation necrosis (black arrow) in an exophytic GA and deposition of hyaline layers of organic matrix (arrowhead); scale bar $=60 \mu \mathrm{m}$. (E) Same as $(\mathrm{A})$; note hyaline material deposition (black arrow) and necrosis in nodular GAs; scale bar $=30 \mu \mathrm{m}$. (F) Crateriform GAs in A. monticulosa with endobionts; note sponges (black arrow) associated with necrosis and deposition of hyaline laminae (arrowhead) in coral tissue; scale bar $=400 \mu \mathrm{m}$. 


\section{DISCUSSION}

Acropora GAs were found in all 3 regions, but the reefs of Tutuila had the widest distribution and largest variety and number of morphological types. Host density does not appear to explain this phenomenon because the average density of Acropora was similar in the 3 regions. Similarly, Willis et al. (2004) found GAs to be uncommon on the Great Barrier Reef even though Acropora is the dominant coral.

The etiology of Acropora GAs is unknown, but a number of hypotheses have been proposed. Peters et al. (1986) and Coles \& Seapy (1998) suggested that damage to cells from ultraviolet (UV) radiation was a potential mechanism contributing to formation of GAs in corals. Peters et al. (1986) found GAs on A. palmata at a reef in the Florida Keys that was subject to environmental stressors such as high levels of sedimentation, turbidity and seasonal temperature extremes and suggested that environmental factors may have a role in formation of coral GAs. Environment may partly explain the relatively higher prevalence of GAs in Tutuila; Tutuila differs from the other 2 sites in that it is a high island with high human populations and extensive watersheds (with attendant runoff and siltation) compared to Johnston Atoll and FFS, which are both low atolls. Similarly, Aeby et al. (2006) found Porites GAs to be much more common on the reefs of the inhabited main Hawaiian Islands as compared to the relatively more pristine reefs of the Northwestern Hawaiian Islands.

The reefs of Tutuila had all 7 morphologic types of GAs as compared to only 2 morphologic types found at FFS and 1 found at Johnston Atoll. Tutuila also has the highest number of Acropora species ( $\mathrm{n}=25$ species) (Mundy 1996) as compared to Johnston Atoll ( $\mathrm{n}=10$ species) and FFS ( $\mathrm{n}=7$ species) (Maragos et al. 2004). Presumably, a greater number of different host types could lead to greater diversity of GAs. Of the 7 types of GAs, exophytic GAs appeared to be the most common and were found on branching, encrusting and plating colonies. However, we had not devised our morphologic classification of GAs during the surveys, and so our examination of the frequency of occurrence of particular types and their relationship with specific coral colony morphologies was based on a sub-sample of the GAs encountered on the reef. Further studies are needed to verify these findings. Unlike Cheney (1975), we did not see GAs in A. formosa or other species of the staghorn morphology.

Hyperplasia of basal body wall with significantly reduced numbers of polyps and zooxanthellae in Acropora from the Indo-Pacific confirmed the findings of Peters et al. (1986) in A. palmata. Reduced numbers of zooxanthellae would explain the translucence of tissues (white color) seen in most GAs, although some corals with decreased zooxanthellae were gray. Unlike Peters et al. (1986), we did not see significant increases in cellularity or decreased nematocysts in GAs. Methodology may account for the discrepancy. Peters et al. (1986) quantified cellularity and nematocyts over a surface area, whereas we quantified cellularity along a linear contour. Hyperplastic basal body wall in GAs quantified over a surface area may result in multiple tangential sections having the appearance of hypercellularity potentially producing artificially increased cell counts. Alternatively, Peters et al. (1986) quantified GAs from a single species of Acropora, while we pooled different GAs from different species to increase statistical power and to answer the more general question of what differences existed between GAs and normal tissues in Acropora. Clearly, future studies will need to assess whether patterns seen in the present study can be applied to particular morphologies across a wider range of corals and geographic areas. A final possibility is that, compared to Acropora in the Pacific, GAs in A. palmata from the Caribbean have a different microscopic morphology.

Peters et al. (1986) showed that GAs in Acropora palmata are progressive leading to death of surrounding normal tissue, and the present study confirms this phenomenon, at least in the colonies where we had sequential data. Larger GAs seemed to preferentially undergo tissue loss; however, confirming the generality and mechanisms of these phenomena awaits more targeted studies. Microscopic evidence of apparently spontaneous necrosis in $41 \%$ of intact GAs in the absence of associated organisms such as fungi or algae provides a clue into possible early stages of degeneration of these GAs. Selective necrosis of mesenterial filaments may explain the reduced number of polyps in GAs (e.g. polyp structures die before the full polyp can develop or mature). Rounding of cells in some GAs was morphologically suggestive of apoptosis (Vermeulen et al. 2005), and use of molecular markers to localize apoptosis signaling molecules in coral cells may shed light on this phenomenon (Hewitson et al. 2006). Why necrosis in GAs assumes 3 forms (cellular rounding, diffuse necrosis and diffuse necrosis with deposition of hyaline matrix layers) remains open to question; however, necrosis in GAs is not necessarily dependent on invasive organisms such as algae or fungi.

In higher vertebrates, necrosis of tumors typically occurs either because rapidly growing neoplastic cells outgrow their blood supply (anoxia) or because toxic factors associated with tumor invasiveness lead to cell death (toxemia) (Cheville 1976). Coral polyps absorb oxygen directly from the water, so anoxia would not be a likely explanation for necrosis. Like Peters et al. (1986), we found continuity in gastrovascular canals between normal and GA tissues, but circulation within 
gastrovascular canals of GAs could be compromised and this topic merits further analyses. Toxemia due to altered metabolism (Cheney 1975) of GA tissue or inadequate food supply for such rapid growing tissue are other possible explanations of necrosis. In sum, tissues from GAs are compromised functionally (reduced numbers of polyps leading to reduced food capture), structurally (necrosis) and reproductively (reduced development of gonads), exerting a negative cost on the colony. Costs in terms of reduced growth due to GAs have also been found (Cheney 1975, Bak 1983). As such, the effect of Acropora GAs on the overall health of reef systems is a concern.

Spatial analysis of GAs on 2 acroporid colonies showed a clustered distribution of GAs within colonies. Whether these 2 colonies represent the usual distribution of GAs on acroporids or are the exception needs to be verified; however, we commonly see this pattern in the field. Clustering of GAs within colonies may be explained either by metastasis (dissemination of GA cells from Point A to B) or by de novo generation of GAs. In the present study the absence of mitotic figures, hypercellularity and invasiveness in tissues from GAs argue against metastasis (Cheville 1976). On the other hand, little is known regarding morphologic indicators of neoplasia and metastasis in invertebrates, so this phenomenon cannot be ruled out completely. A second hypothesis is that factors locally secreted from GAs promote growth of GAs in the immediate area (paracrine effect). A final possibility is that a locally communicable agent (such as a virus that is transmitted cell to cell) is responsible for clustered growth patterns of GAs within colonies. However, attempts to transmit GAs among corals have been unsuccessful (Cheney 1975, Peters et al. 1986).

We chose to describe the cellular changes seen in Acropora GAs as hyperplasia because we judged that they did not fit the classic definition and morphologic criteria of neoplasia or uncontrolled cell growth (Cheville1976). The concept of neoplasia continues to elicit uncertainty even for vertebrate medicine (Cheville 1976). Peters et al. (1986) concluded that GAs in A. palmata were neoplasias based on observations of irreversible growth leading to death. Dawe (1969) and Sparks (1972) urged caution in applying the criteria used to define neoplasia in vertebrates for invertebrates. In spite of these reservations, vertebrate medicine currently offers the best and most complete criteria for defining neoplasia in animals, and thus may provide an adequate basis for determining the nature of GAs in corals. Cheville (1976) noted that all neoplasias share certain commonalities including (1) cell surfaces designed for movement, (2) simplified energy production, (3) failure of differentiation (nuclear pleomophism and prominent nucleoli); and (4) inconsistent presence of mitotic figures. The latter 2 criteria highlight the important role that morphology plays in characterizing neoplasia, and these features were not seen in samples from the present study. Mix (1986) noted that the hallmark characteristic of vertebrate neoplasms (e.g. metastasis) were not always present in socalled neoplasms of mollusks and other invertebrates. Nevertheless, it has become generally accepted that neoplasia is a condition probably found throughout the animal kingdom.

A significant factor in the uncertainties surrounding GAs in corals is lack of information (Peters 1997). Given current data, certain commonalities of GAs in corals of the family Acroporidae are emerging. At the gross level these include more rapid growth compared to normal tissues (Cheney 1975, Peters et al. 1986), irreversible growth leading to reduced colony growth, partial or complete death of the colony (Peters et al. 1986, Coles \& Seapy 1998, Yamashiro et al. 2000, the present study), reduced polyp density (Peters et al. 1986, Yamashiro et al. 2000, the present study) and lower skeletal density (Cheney 1975, Peters et al. 1986, Yamashiro et al. 2000, the present study). At the cellular level GAs are exemplified by reduced mesenterial filaments (Peters et al. 1986, Yamashiro et al. 2000) and lack of anaplasia (Peters et al. 1986, the present study). Future efforts should focus on confirming or refuting these morphologic commonalities and critically evaluating whether they fit the criteria used to define neoplasia for vertebrates. Meanwhile, given the current uncertainties regarding this topic, 'growth anomaly', rather than 'tumor', may be a preferable term for this condition in corals since the latter implies neoplasia.

Acknowledgements. E. Peters, F. Morado, S. McLaughlin and anonymous reviewers provided critiques. We are grateful for funding for portions of this work from the American Samoa Coral Reef Advisory Group, NOAA and the US Fish \& Wildlife Service. We thank D. Fenner and C. Birkeland for their assistance in the identification of many of the coral species listed here.

\section{LITERATURE CITED}

Aeby G, Work T, Coles S, Lewis T (2006) Coral disease across the Hawaiian archipelago. Ocean Sci Meet Suppl, Abstract OS24L-03. EOS (Trans Am Geophys Union) 87:36

Amerson AB (1971) The natural history of French Frigate Shoals, Northwestern Hawaiian Islands. Atoll Res Bull 150:1-383

Amerson AB, Shelton PC (1976) The natural history of Johnston Atoll, Central Pacific Ocean. Atoll Res Bull 192:1-480

Bak RPM (1983) Neoplasia, regeneration and growth in the reef-building coral Acropora palmata. Mar Biol 77:221-227

Cheney DP (1975) Hard tissue tumors of scleractinian corals. Adv Exp Med Biol 64:77-87 
Cheville NF (1976) Cell pathology. Iowa State University Press, Ames, IA

Clark PJ, Evans FC (1954) Distance to nearest neighbor as a measure of spatial relationships in populations. Ecology 35:445-453

Coles SL, Seapy DG (1998) Ultra-violet absorbing compounds and tumorous growths on acroporid corals from Bandar Khayran, Gulf of Oman, Indian Ocean. Coral Reefs 17:195-198

Dawe CJ (1969) Phylogeny and oncogeny. Nat Cancer Inst Monogr 31:1-39

Green AL, Birkeland CE, Randall RH (1999) Twenty years of disturbance and change in Fagatele Bay National Marine Sanctuary, American Samoa. Pac Sci 53: 376-400

Hewitson TD, Bisucci T, Darby IA (2006) Histochemical localization of apoptosis with in situ labeling of fragmented DNA. Methods Mol Biol 326:227-234

Kenyon JC, Vroom PS, Page KN, Dunlap MJ, Wilkinson CB, Aeby GS (2006) Community structure of hermatypic corals at French Frigate Shoals, Northwestern Hawaiian Islands capacity for resistance and resilience to selective stressors. Pac Sci 60:153-175

Maragos JE, Jokiel PL (1986) Reef corals of Johnston Atoll: one of the world's most isolated reefs. Coral Reefs 4 $141-150$

Maragos J, Potts D, Aeby G, Gulko D, Kenyon J, Siciliano D, VanRavensway D (2004) The 2000 to 2002 rapid ecological assessment of corals in the Northwestern Hawaiian Islands. Part I. Species and distribution. Pac Sci 58: 211-230

Mix MC (1986) Cancerous diseases in aquatic animals and their association with environmental pollutants: a critical

Editorial responsibility: Rick Cawthorn, Charlottetown, Prince Edward Island, Canada literature review. Mar Environ Res 20:1-141

Mundy C (1996) A quantitative survey of the corals of American Samoa. Dept. of Marine and Wildlife Resources, American Samoa Government, Pago Pago

Peters EC (1997) Diseases of coral-reef organisms. In: Birkeland C (ed) Life and death of coral reefs. Chapman \& Hall, New York

Peters EC, Halas JC, McCarty HB (1986) Calicoblastic neoplasms in Acropora palmata with a review of reports on anomalies of growth and form in corals. J Natl Cancer Inst 76:895-912

Rice WR (1989) Analyzing tables of statistical tests. Evolution 43:223-225

Sparks AK (1972) Invertebrate pathology: non-communicable diseases. Academic Press, New York

Squires EJ (1965) Neoplasia in a coral? Science 148:503-505

Sutherland KP, Porter JW, Torres C (2004) Disease and immunity in Caribbean and Indo-Pacific zooxanthellate corals. Mar Ecol Prog Ser 266:273-302

Vermeulen K, Van Bockstaele DR, Berneman ZN (2005) Apoptosis: mechanisms and relevance in cancer. Ann Hematol 84:627-639

Willis BL, Page CA, Dinsdale EA (2004) Coral disease on the Great Barrier Reef. In: Rosenberg E, Loya Y (eds) Springer, Berlin, p 69-104

Work TM, Aeby GS (2006) Systematically describing gross lesions in corals. Dis Aquat Org 70:155-160

Work TM, Rameyer RA (2005) Characterizing lesions in corals from American Samoa. Coral Reefs 24:384-390

Yamashiro H, Yamamoto M, van Woesik R (2000) Tumor formation on the coral Montipora informis. Dis Aquat Org 41:211-217

Submitted: January 18, 2007; Accepted: November 4, 2007 Proofs received from author(s): January 11, 2008 